\title{
PALEONTOLOGICAL METHODS IN ENVIRONMENTAL SCIENCE
}

BRUSH, Grace S.; KHAN, Humaira*, Department of Geography and Environmental Engineering, Johns Hopkins University, 34 th and $N$. Charles Sts., Baltimore, MD 21218, U.S.A.

Long term environmental changes, induced both by natural and anthropogenic causes, cannot be assessed by looking solely at historical records of temperature, rainfall, water quality, etc. Frequently, wuch records are nonexistent. Where they do exist, they are often too short to be of much use. However, sediments contain a stratigraphic record of environmental change that allows comparison of the historic period influenced largely by humans, with prehistoric time when climate was the major determinant of environmental conditions.

The stratigraphic record contains various fossilized organic materials which reflect environmental conditions at the time of the their deposition. Most abundant are pollen and spores of aquatic and terrestrial plants. Correspondence between pollen assemblages and vegetation has been found in all parts of the world. Therefore stratigraphic changes in pollen taxa reveal much information regarding the vegetational history of a region. Knowledge of the ecological requirements of various taxa can then be used to infer past climatic conditions. For example, dominance of Juglans (walnut) pollen indicates wet conditions while abundance of Pteridium (bracken fern) spores is an indicator of fire, suggesting drier conditions. Pollen can also be used to trace human disturbance to the environment. Sharp increases in the pollen of Ambrosia (ragweed) in sediment cores indicate large scale land clearance by man.

Seeds preserved in sediments provide another measure of temporal vegetational change. Generally, seeds are not dispersed far from the parent plant; hence they provide a more local record of vegetation than pollen. A decrease in seeds of aquatic plants and increase in seeds of higher ground taxa when accompanied by increased sedimentation rates is an indicator of infilling of an aquatic environment. If unaccompanied by increased sedimentation, the change more likely represents lowering of sea level. Disappearance of seeds of taxa sensitive to turbidity and eutrophication provide another long term record of human disturbance.

Distributions of diatoms are affected by temperature, salinity, oxygen, light availability and nutrient levels in the water.

Therefore changes in diatom species preserved in the sediments can be used as indicators of climate, turbidity, anoxia and eutrophication in aquatic ecosystems.

Many inorganic substances preserved in sediments also provide a long term record of changes in the environment. Nitrogen and phosphorus can be measured in cores and used as a surrogate record of water quality in lakes and estuaries. Sharp increases in sedimentary accumulation of metals record wastewater discharge and fuel emissions, related to human activity. 